\title{
Contingency theory and the effect of the duration of signals for noncontingent reinforcement
}

\author{
BEN A. WILLIAMS \\ University of California, San Diego, La Jolla, California
}

\begin{abstract}
Rats learned to approach a light that signaled food when food occurred only after the signal, but did not approach the light when food was equally probable regardless of the signal. When food unpaired with the light was preceded by a 5-sec noise, little learning was evident as well, but when the unpaired food was preceded by a 15-sec noise, approach to the light conditioned stimulus readily occurred. These effects of signal duration are similar to those previously obtained with the effect of free food on free-operant behavior and challenge existing theories of contingency effects in Pavlovian conditioning.
\end{abstract}

Contingency relations have been studied in tasks as diverse as Pavlovian conditioning in pigeons and category learning in humans. Whether the same principles underlie contingency effects in all of these settings remains a subject of controversy, as some investigators have argued that such effects can be reduced to associative learning theory (e.g., Chapman, 1991; Shanks \& Dickinson, 1987; Wasserman, 1990), while others have argued that more cognitive explanations are required (e.g., Waldmann \& Holyoak, 1992). A major difficulty in resolving this issue is that the basis for contingency effects in simple conditioning experiments is inadequately understood in its own right.

In both Pavlovian and instrumental conditioning, the conditioning effect of a constant set of pairings, either between the conditioned stimulus (CS) and reinforcer in Pavlovian conditioning, or between the response and reinforcer in instrumental conditioning, is degraded by the addition of unpaired reinforcers to the conditioning situation. Despite their apparent similarity, these contingency effects for the two types of conditioning have received different theoretical interpretations. For Pavlovian conditioning, the dominant interpretation, derived from the conditioning model of Rescorla and Wagner (1972), has been made in terms of "context blocking." 'The unpaired reinforcers are assumed to become associated with the background cues, which, because they are present during conditioned stimulus-unconditioned stimulus (CS-US) pairings, effectively compete with the nominal CS for further association with the reinforcer (see Durlach, 1989, for a review). For instrumental conditioning, the dominant interpretation has been made in terms of the concept of relative rate of reinforcement, which has been assumed to be the fundamental variable controlling response rate (e.g., Herrnstein, 1970; Rachlin \& Baum, 1972).

This research was supported by NSF Grant BNS 9010323 to the University of California, San Diego. Reprint requests should be addressed to the author, Department of Psychology, UCSD, La Jolla, CA 92093-0109.
A critical type of evidence pertaining to the contextblocking interpretation of Pavlovian contingency effects has been the effects of signaling the unpaired reinforcers that are added during the intertrial interval (ITI). If context blocking were the mechanism, signaling the extra reinforcers should reduce the context-reinforcer association and thus reduce the amount of blocking by the context of the CS-US association. Responding to the CS should then be more likely when the extra reinforcers are signaled rather than unsignaled. Although in several studies researchers (Balsam, 1982; Jenkins, Barnes, \& Barrera, 1981; Jenkins \& Lambos, 1983) have failed to find such effects, others (Durlach, 1983; Goddard \& Jenkins, 1987; Grau \& Rescorla, 1984) have found strong effects of signaling.

Signaling noncontingent reinforcers has also been shown to attenuate their response-decrementing effects in freeoperant procedures (Colwill \& Rescorla, 1986; Dickinson \& Charnock, 1985; Hammond \& Weinberg, 1984; Williams, 1989). This similarity in the effects of signals for Pavlovian as opposed to operant conditioning suggests that a similar mechanism may underlie both procedures. Again, however, the interpretation given to the signaling effects on the two types of conditioning has been different. Williams (1989) suggested that the effects of the signals in the operant procedure were due to their allowing a discrimination between two contingencies. In the absence of the signal, only response-contingent reinforcement was available, whereas during the signal, reinforcement was delivered independently of responding. In support of this discrimination interpretation, Williams (1989) demonstrated that signals significantly reduced the response-decrementing effects of free reinforcers only when the signals were relatively long $(12 \mathrm{sec})$, with the reduction in response rate by free reinforcers preceded by shorter signals $(4 \mathrm{sec})$ being not significantly different from the reduction that occurred when the free reinforcers were unsignaled. This effect seemed consistent with the discrimination interpretation, because the longer signal allowed a greater temporal separation between the two types of contingencies. 
Whatever the explanation of the effect of signal duration reported by Williams (1989), a comparable effect with Pavlovian procedures would challenge the contextblocking interpretation of contingency effects. According to that interpretation, the ability of the signal for the ITI reinforcers to prevent context blocking should depend on the degree to which the signal competes with background cues for association with the reinforcer, and hence the rate and/or strength of conditioning to the signal itself. It is well known that the degree of conditioning is inversely related to the CS-US interval, which implies that shorter signals, not longer signals, should produce greater conditioning to the signal for the ITI reinforcers. Thus, more context blocking should occur with the shorter signals, which is the opposite pattern of results from that actually observed. However, it remains unclear whether the effects of signal duration that have occurred with instrumental conditioning will also occur with Pavlovian conditioning. The present study is thus an investigation of whether the same pattern of results will occur.

In addition to determining whether signal duration determines the effects of reinforcers presented in the ITI, the present study also introduces a new Pavlovian procedure with rats as subjects. The procedure involves approach to the signal for the food reinforcer, with the signal and reinforcer located at different sites in the chamber. A modified shuttlebox is used, in which the light CS appears at either end of the chamber, with the food magazine located in the center of the chamber, midway between the two potential CSs. The measure of conditioning, then, is whether or not the subject will move to the side of the chamber on which the CS is presented on a given trial.

\section{METHOD}

\section{Subjects}

Twenty-five experimentally naive male albino Sprague-Dawley rats, ranging in age from 3 to 6 months, served as subjects. Food deprivation was maintained by allowing $90 \mathrm{~min}$ of access to laboratory chow each day approximately $5 \mathrm{~min}$ after the end of the experimental sessions. Water was continuously available in the home cages at all times. The subjects were housed in individual cages with 14:10-h light:dark cycle. The experiment was conducted during the light-on part of the cycle, in the morning and early afternoon hours.

\section{Apparatus}

The experimental chamber was a converted shock-avoidance shuttlebox manufactured by Davis Scientific Instruments. The rat's chamber was $30.5 \mathrm{~cm}$ in width, $64 \mathrm{~cm}$ in length, and $22 \mathrm{~cm}$ in height. Three of the four sidewalls were sheet metal, the fourth was a glass door, which extended the entire length of the chamber. The floor of the chamber was constructed of copper rods, $1.2 \mathrm{~cm}$ in width and spaced $2.0 \mathrm{~cm}$ apart, center to center. Mounted in the ceiling of the chamber were two $4.0-\Omega$ Quam speakers, each $15 \mathrm{~cm}$ from their respective ends of the chamber. White noise generated by a Gerbrands noise generator (Model G4651) was delivered to both speakers simultaneously, with an approximate intensity of $88 \mathrm{~dB}$ (SPL). Also mounted in the ceiling, at its midpoint, were four miniature lamps, all of which were illuminated simultaneously throughout an experimental session to serve as a houselight. Mounted in the middle of each end wall was a 28-V miniature bulb (No. 1820), covered by a red glass cover, which served as the CS. Mounted in the center of the rear wall was a food magazine, into which $45-\mathrm{mg}$ Noyes pellets (improved formula A) were delivered by a Gerbrands magazine feeder located outside of the experimental chamber. All of the above were mounted in a larger exterior chamber equipped with a ventilating fan.

\section{Procedure}

Subjects received no preliminary training except that five food pellets were placed in the food magazine at the start of the first session of training. The session consisted of 120 intervals, each $15 \mathrm{sec}$ in duration. Four experimental conditions were defined by the events during these periods. For the CS-only group, CS trials were presented with a probability of .15. The CS was a 15-sec presentation of one of the two red panel lights located at either end of the experimental chamber. Which end of the chamber had the illuminated light on a given CS trial was randomly varied across trials. The probability of food at the end of a CS trial was .5. Food occurred at no other times during the session.

For the no-signal group, the same schedule of CS trials was presented. In addition, food was presented with a probability of .5 at the end of each 15-sec period without the CS.

For the long-signal group, the same schedule of CS presentations was again used, and the probability of food on 15 -sec periods without the CS was also .5. Now, however, these no-CS food presentations were preceded by a 15 -sec presentation of a white noise from the overhead speakers. This meant that approximately $40 \%-45 \%$ of all trial periods were filled by the white noise, and that trial periods with neither the CS nor the noise also filled $40 \%-45 \%$ of the session.

For the short-signal group, the same procedure as that for the longsignal group was used, except that the white noise filled only the last $5 \mathrm{sec}$ of the periods in which the no-CS food presentations were delivered, rather than the entire $15 \mathrm{sec}$

Training for the CS-only group continued for 20 experimental sessions. Training for the remaining three groups continued for 40 sessions. Six subjects were assigned to each group, with the exception of the long-signal condition, which was assigned 7 subjects.

\section{RESULTS}

Figure 1 shows the results over the course of acquisition in terms of the percentage of time spent on the side of the chamber with the signal during the last $5 \mathrm{sec}$ of the 15-sec CS duration. Results for the entire CS period were similar but with smaller effects because it took the subjects some time to react to the signal after its onset. The subjects in the CS-only condition received only 20 sessions of training, because they acquired the tendency to approach the CS much faster than the remaining three groups with additional reinforcers during the ITI periods. Very little evidence of acquisition had occurred during

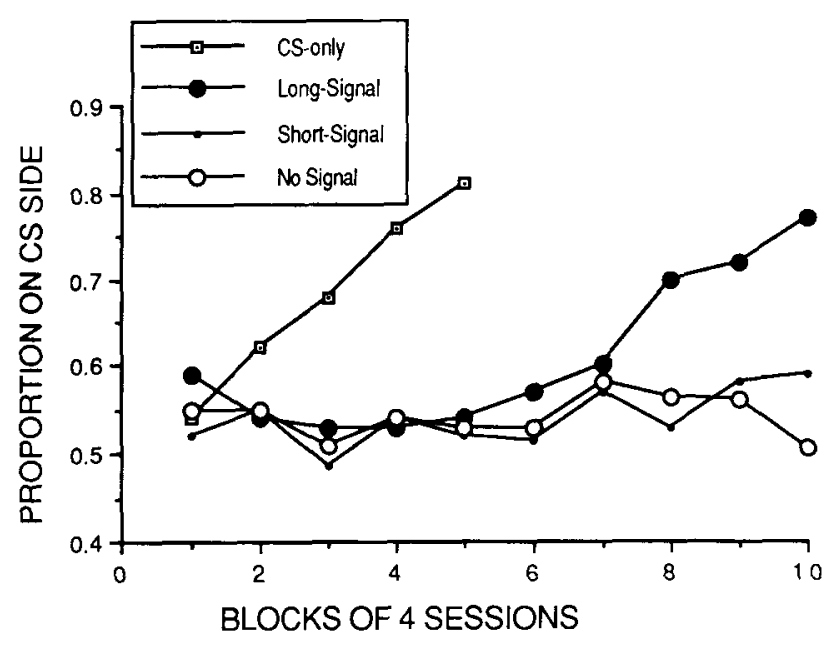

Figure 1. Proportion of time on the side of the chamber with the conditioned stimulus (CS) during the last $5 \mathrm{sec}$ of $\mathrm{CS}$ trials, during the course of acquisition. 
the first 20 sessions for any of the remaining three groups. However, with continued training, the long-signal condition developed clear differential responding to the CS, while substantially lower levels of approach to the CS occurred for the short-signal and no-signal groups, although both were generally above the .5 level of time allocation during the last several blocks of training.

The results shown in Figure 1 were analyzed with two separate analyses of variance (ANOVAs) (groups $\times$ blocks) with a .05 significance level. The first analysis was restricted to the first 20 sessions, and included all four groups. Here the main effect of groups was significant $[F(3,21)=12.81]$ as was the main effect of blocks $[F(4,84)=3.51]$ as well as their interaction $[F(12,84)=$ 6.15]. An analysis of simple effects showed that the blocks effect was significant only for the CS-only condition. Newman-Keuls tests were used to analyze the differences between individual means: the CS-only group was found to be significantly different from each of the remaining three groups, and none of the remaining three groups were different from each other.

The second ANOVA included all 40 sessions, and was restricted to the long-signal, short-signal, and no-signal conditions. Here the main effect of groups was again significant $[F(2,16)=6.35]$, as was the main effect of blocks $[F(9,144)=9.43]$, as well as the interaction $[F(18,144)=4.69]$. An analysis of simple effects showed that the blocks effect was significant for the long-signal and the short-signal conditions, but not for the no-signal condition. Newman-Keuls tests were used to compare individual pairs of groups: the long-signal group was significantly different from both the short-signal and the nosignal conditions, but the latter two conditions were not significantly different.

\section{DISCUSSION}

The general pattern of results was similar to those obtained by Williams (1989) using an instrumental learning procedure in which free reinforcers were superimposed on a free-operant baseline. The degradation of control by the reinforcement contingency with respect to the CS was attenuated when the free reinforcers were preceded by a long signal, but was relatively little affected when preceded by a short signal. As in Williams (1989), there was some evidence of a small effect of the short signal, in that a significant effect of blocks did occur with that condition, but the signaling effects were substantially greater with the longer signal.

Examination of previous studies done with signaled ITI reinforcers leaves uncertain whether differences in signal duration can account for the conflicting results that have been obtained. Signaling effects have most typically been found with the use of signals $10 \mathrm{sec}$ in duration (e.g., Durlach, 1983), but some failures to find a signaling effect (Jenkins et al., 1981) have occurred with the use of signals that were of similar duration (8 and $10 \mathrm{sec}$ in two separate experiments), although with many other procedural differences. I have found no reports of signal effects found with durations less than $10 \mathrm{sec}$ in Pavlovian procedures. Studies of contingency effects with instrumental conditioning have shown strong effects of signals with durations of 4 or $5 \sec$ (Dickinson \& Charnock, 1985; Hammond \& Weinberg, 1984), but these have involved explicit reinforcement contingencies for not responding during the signal that might be more easily discriminated than simpler contingency effects. Other studies with very brief signals $(1-2 \mathrm{sec})$ have failed to find any difference between signaled and unsignaled free reinforcement added to a baseline of response-contingent reinforcement (Duncan \& Silber- berg, 1982; Rachlin \& Baum, 1972). In none of these previous studies have the effects of different signal durations been directly compared.

The present findings conflict with those reported by Cooper, Aronson, Balsam, and Gibbon (1990), who did compare the effect of different signal durations. In their study, in an autoshaping procedure with pigeons as subjects, reinforcers presented during the ITI were preceded by signals of different durations for different groups of subjects. Contrary to the present findings, responding to the CS developed only in their short-signal condition. It should be noted, however, that their signal durations were substantially different from those used here: their short signal was $12 \mathrm{sec}$ in duration and their long signal was $48 \mathrm{sec}$ in duration, in comparison with the present values of 5 and $15 \mathrm{sec}$. Thus, their short-signal duration was similar to the long-signal duration in the present study, suggesting that there may be an inverted U-shaped function relating signal duration to the degree of conditioning to the CS. It is also possible that the critical duration of the signal may vary with the average interreinforcement interval, which was $30 \mathrm{sec}$ in the present study, but $60 \mathrm{sec}$ in Cooper et al. (1990). Any direct comparison of the two studies is of course problematic, both because of the many other parameter differences between the two studies, and because of the use of different conditioning preparations.

The present findings are nevertheless relevant to the theoretical interpretation offered by Cooper et al. (1990) for their findings on the effect of signal duration. Noting that any effect of signaling the ITI reinforcers is incompatible with the SET comparator account of Pavlovian conditioning (Gibbon \& Balsam, 1981), they argued that a modification, known as the "deletion comparator" model, could encompass their findings, along with many others showing that signal conditions associated with the "noncontingent" reinforcers are important (see, e.g., Brandon, 1981; Farley, 1980; Williams, 1976). According to this modified comparator theory, alternative signals demarcate separate time periods, so that the time periods associated with the alternative signals, and the ITI reinforcers delivered during them, are not included in the computation of the background rate of reinforcement, to which the rate of reinforcement during the CS is compared. Thus, the longer the signal, the smaller the remaining amount of time included in the background period, so that a given rate of reinforcement during the CS results in the computation of a higher rate of reinforcement associated with the background and slower conditioning to the CS. Conversely, shorter signals produce longer background periods and thus faster rates of conditioning to the CS. The opposite effect of signal duration in the present study challenges this interpretation, because it makes clear that the effect of signal duration cannot be understood simply in terms of how signals affect the computation of background rate of reinforcement. According to the "deletion comparator" account, the rate of CS reinforcement relative to background reinforcement rate in the present study was 6.7:1 for the CS-only condition, 1:1 for the no-signal condition, 3.8:1 for the long-signal condition, and 5.7:1 for the short-signal condition. Thus, acquisition should have occurred most readily in the CS-only and short-signal conditions, and more slowly during the long-signal condition. Instead, the effect of signal duration was in the reverse direction.

The present results also pose difficulties for the alternative explanation in terms of context blocking. As noted in the introduction, that explanation entails that the degree of blocking of conditioning to background cues should be directly related to the strength of conditioning to the signal, which is presumably greater with shorter signals. It should be recognized, however, that this is an assumption about which there is little direct evidence. It is possible, for example, that the usual finding of greater conditioned responding to a short CS may be only a performance effect and not correspond to the ability of the stimulus to cause blocking to other stimuli in the situation. To our knowledge, the actual effect of the duration of a stimulus on its ability to produce blocking has not been empirically investigated.

The context-blocking interpretation of contingency effects might also be reconciled with the present results by the assumption that the signal for the ITI reinforcers served two different functions: In addition to competing with the contextual cues for association with the primary reinforcer, they may also serve as a source of second-order conditioning. Such second-order conditioning of context by Pavlovian CSs has been directly demonstrated by Rescorla (1984). Accordingly, the longer signals in the present study would be assumed to provide less second-order conditioning of the contextual cues because longer CSs are themselves less 
strongly associated with the US. Such an assumption entails that the total amount of conditioning of the background cues, and hence the degree of competition with the target CS, is determined by two different effects of the signals for the ITI reinforcers: second-order conditioning effects that should increase the context conditioning and blocking effects that attenuate the context conditioning by the primary reinforcer. The obvious weakness of this explanation is that it requires these two separate and opposing processes to summate in their effects in just the right manner to produce the obtained pattern of results. The explanation also does not easily account for previous results of different types of signal arrangements on the degree of instrumental conditioning (see Williams, 1989, Experiment 3).

Regardless of the merits of the preceding account, the present results are important because they demonstrate still another isomorphism between contingency effects in Pavlovian and instrumental conditioning, and thus encourage a unified theoretical account of both domains. It remains to be seen what type of account can encompass the effects of signal duration and the variety of other similar effects that have been demonstrated.

\section{REFERENCES}

BALSAM, P. D. (1982). Bringing the background to the foreground: The role of contextual cues in autoshaping. In $\mathbf{M}$. Commons, R. Herrnstein, \& A. Wagner (Eds.), The Harvard Symposium on the Quantitative Analysis of Behavior: Acquisition processes (pp. 145-171). Cambridge, MA: Ballinger Press.

BRANDON, S. E. (1981). Key-light-specific associations and factors determining key pecking in noncontingent schedules. Journal of Experimental Psychology: Animal Behavior Processes, 9, 374-389.

Chapman, G. B. (1991). Trial order affects cue interaction in contingency judgment. Joumal of Experimental Psychology: Learning, Memory, \& Cognition, 17, 837-854.

Colwill, R. M., \& Rescorla, R. A. (1986). Associative structures in instrumental learning. In G. H. Bower (Ed.), The psychology of learning and motivation (Vol. 20, pp. 55-104). San Diego, CA: Academic Press.

Cooper, L. D., Aronson, L., Balsam, P. D., \& Gibbon, J. (1990). Duration of signals for intertrial reinforcement and nonreinforcement in random control procedures. Journal of Experimental Psychology: Animal Behavior Processes, 16, 14-26.

Dickinson, A., \& Charnock, D. J. (1985). Contingency effects with maintained instrumental reinforcement. Quarterly Journal of Experimental Psychology, 37B, 397-416.

Duncan, H. J., \& SilberberG, A. (1982). The effects of concurrent responding and reinforcement on behavioral output. Journal of the Experimental Analysis of Behavior, 38, 125-132.

DURLACH, P. J. (1983). Effect of signaling intertrial unconditioned stimuli in autoshaping. Journal of Experimental Psychology: Animal Behavior Processes, 9, 374-389.

DURLACH, P. J. (1989). Learning and performance in Pavlovian conditioning: Are failures of contiguity failures of learning or performance? In S. B. Klein \& R. R. Mowrer (Eds.), Contemporary learning theories: Pavlovian conditioning and the status of traditional learning theory (pp. 19-59). Hillsdale, NJ: Erlbaum.

FARLEY, J. (1980). Automaintenance, contrast, and contingencies: Ef- fects of local vs. overall and prior vs. impending reinforcement context. Learning \& Motivation, 11, 19-48.

GibBon, J., \& Balsam, P. (1981). Spreading association in time. In C. M. Locurto, H. S. Terrace, \& J. Gibbon (Eds.), Autoshaping and conditioning theory (pp. 219-253). New York: Academic Press.

GoDdARD, M. J., \& JENKINs, H. M. (1987). Effect of signaling extra unconditioned stimuli on autoshaping. Animal Learning \& Behavior, $15,40-46$.

GraU, J. W., \& ResCorla, R. A. (1984). Role of context in autoshaping. Journal of Experimental Psychology: Animal Behavior Processes, 10, 324-332.

Hammond, L. J., \& Weinberg, M. (1984). Signaling unearned reinforcers removes the suppression produced by a zero correlation in an operant paradigm. Animal Learning \& Behavior, 12, 371-377.

HERRNSTEIN, R. J. (1970). On the law of effect. Journal of the Experimental Analysis of Behavior, 13, 243-266.

JeNkins, H. M., BARNES, R. A., \& BARRERA, F. J. (1981). Why autoshaping depends on trial spacing. In C. M. Locurto, H. S. Terrace, \& J. Gibbon (Eds.), Autoshaping and conditioning theory (pp. 219253). New York: Academic Press.

JENKINS, H. M., \& LAMBOs, W. A. (1983). Tests of two explanations of response elimination by noncontingent reinforcement. Animal Learning \& Behavior, 11, 302-308.

RACHLIN, H., \& BAUM, W. M. (1972). Effects of alternative reinforcement: Does the source matter? Journal of the Experimental Analysis of Behavior, 18, 231-241.

Rescorla, R. A. (1984). Associations between Pavlovian CSs and context. Journal of Experimental Psychology: Animal Behavior Processes, 8, 131-141.

Rescorla, R. A., \& Wagner, A. R. (1972). A theory of Pavlovian conditioning: Variations in the effectiveness of reinforcement and nonreinforcement. In A. H. Black \& W. F. Porasky (Eds.), Classical conditioning II: Current research and theory (pp. 64-99). New York: Appleton-Century-Crofts.

SHANKs, D., \& Dickinson, A. (1987). Associative accounts of causality judgement. In G. H. Bower (Ed.), The psychology of learning and motivation: Vol. 2I. Advances in research and theory (pp. 229-261). New York: Academic Press.

Waldmann, M. R., \& Holyoak, K. J. (1992). Predictive and diagnostic learning within causal models: Asymmetries in cue competition. Journal of Experimental Psychology: General, 121, 222-236.

Wasserman, E. A. (1990). Attribution of causality to common and distinctive elements of compound stimuli. Psychological Science, 1, 298-302.

WILLIAMS, B. A. (1976). Elicited responding to signals for reinforcement: The effects of overall versus local changes in reinforcement probability. Journal of the Experimental Analysis of Behavior, 26, 213-220.

Williams, B. A. (1989). Signal duration and suppression of operant responding by free reinforcement. Learning \& Motivation, 20 , 335-357.

(Manuscript received June 22, 1993; revision accepted for publication August 28, 1993.) 